\title{
A Research Paper on Fabrication of Compressed Air Tank
}

\author{
Prof.S.S.Pawar ${ }^{1}$, Priyanka R Giripunje ${ }^{2}$, Vikant D Ghathbandhe, \\ Amol M Rajpande ${ }^{4}$, Dhananjay R Katre ${ }^{5}$ \\ ${ }^{1}$ Associate Professor, Smt.Radhikatai Pandav College of Engineering,Nagpur,India-441203 \\ ${ }^{2345}$ UG Students, Smt.Radhikatai Pandav College of Engineering, Nagpur,India-441203
}

Received on: 15 May, 2021, Revised on: 17 June, 2021, Published on: 19 June, 2021

\begin{abstract}
Compressors are widely used for many engineering applications in day to day life. Compressors are classified based on design as reciprocating compressors, Reciprocating compressors are single acting and single stage, depends on application of usage. The analysis also showed that the performance of the compressor was affected by several other factors including the climatic and environmental condition such as the high operating ambient temperature of the inlet air to the compressor. The results further revealed that clogging was a major factor that affected the performance effectiveness of the reciprocating compressor.
\end{abstract}

Keywords- single stage compressor, reciprocating compressor.

\section{I-INTRODUCTION}

C ompressors are of vital importance in modern days industries. They play tremendous role in ensuring that industrial processes and works are done. Compressor are mechanical devices that can compress a substance in gaseous state. When air is used as working fluid in a compressor. This means that an air compressor. This means that an air compressor is a machine that increases the pressure \& temperature of air. During the process of air compression, the inlet/intake pressure of the air is usually raised to a higher exhaust pressure. Air compressor have earned a fair amount of popularity in several industries as a result of popularity in several industries as a result of the various uses of compressed air. Some of such uses and application of compressors are compressed air are in the industries and in equipment. Reciprocating air compressors are widely used to get high discharge pressure. To get high discharge pressure single stage compressor has to work against high compression ratio in terms of pressure so to withstand high compression ratio body of compressor also be made robust in construction.

\section{II- EXPERIMENTATION/FABRICATION}

For the fabrication of fabrication of compressed air tank following types of equipment are used

Pressure Gauge :- A pressure gauge is a fluid intensity measurement device. Pressure gauges are required for the set-up and tuning of fluid power machines, and are indispensable in troubleshooting them. Without pressure gauges, fluid power systems would be both unpredictable and unreliable. Gauges help to ensure there are no leaks or pressure changes that could affect the operating condition of the hydraulic system.

Compressed Air Tank:- In the case of a liquefied gas such as hydrogen or chlorine, or a compressed gas such as compressed natural gas or MAPP, the storage tank must be made to withstand the sometimes immense pressures exerted by the contents. These tanks may be called cylinders and, being pressure vessels, are sometimes excluded from the class of "tanks".

Motor:- A 12v motor is small and inexpensive, yet powerful enough to be used for many applications. 


\section{International Journal of Innovations in Engineering and Science, www.ijies.net}

Because choosing the right this motor for a specific application can be challenging, it is important to work with the right company.

Pipe: - Black pipe is the most commonly used pipe recommended for compressed air systems. It is readily available, it is strong and durable and most people are familiar with how to install it. With all of the advantages black pipe provides, however, it will produce rust contamination that damages pneumatic tooling. The pipe is uncoated, and the presence of moisture will initiate rusting which will increase over time. The presence of moisture can be controlled with an after cooler and/or dryer, but it can never be completely eliminated. Furthermore, the installation of black pipe systems requires significant amount of time. Plan carefully, changes to the system will require depressurizing the system while new drops or additional loops are added.

\section{III-APPLICATION}

Compressed air tanks are most commonly used for filling up tires - on cars, bicycles, trailers, ATVs, etc.but they're also useful for applications using a blow-off tip. The tanks typically are too small for operating air tools for more than a few quick operations. Its relatively light weight and large size make a compressed air tank more useful in the field than a air compressor in many situations. For example, if you need compressed air in any remote location where there's no electricity to run a compressor, you can fill up an air tank at home (or at a gas station or hardware store on your way out) and carry it into the field. The compressed air tank is much lighter than an air compressor with a similarly sized tank.

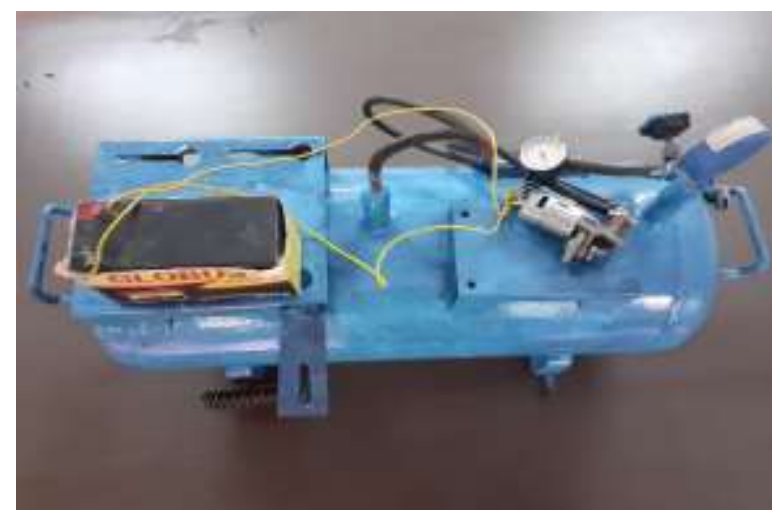

\section{IV-WORKING}

When centrifugal impeller start atmospheric air suck from suction pipe due to high rotation compressed air delivered to the tank.
Air compressors work by forcing air into a container and pressurizing it. Then, the air is forced through an opening in the tank, where pressure builds up. Think of it like an open balloon: the compressed air can be used as energy as it's released. They're powered by an engine that turns electrical energy into kinetic energy. It's similar to how a combustion engine works, using a crankshaft, piston, valve, head and a connecting rod. From there, the pressurized air can be used to power a variety of tools. Some of the more popular options are nailers, impact wrenches, sanders and paint sprayers. There are different types of air compressors and each one has a different specialty. Generally, the differences aren't too severe: it all boils down to the way a compressor handles air displacement.

\section{ADVANTAGES :-}

- It is advanced \& easy to use than regular pumping machine.

- It is not depend on electricity.

- It works on Natural resource.

- It is good because ,It is pollution free.

\section{V- RESULT}

Thus the design and fabrication of compressed air tank using to fill Compressed air into Bicycle tube,Two wheeler tube \& in Baloon. The compressed air tank is better than regular pumping machine.

\section{VI- CONCLUSION}

The compressed is better than regular pumping machine in terms of maintenance, cost and accuracy. The machine frame is carefully designed and cross checking where it does meet the requirements. The scope of the project was making the cost of the compressed air tank as low as possible and increasing its efficiency.

1) Reducing of man power.

2) Time consuming.

\section{REFERANCES}

[1] Internal combustion engines and Air pollution by professor (Dr.) R.Yadav Third revised edition -central publishing house 18-C, Sarojini Naidu Marge-Allahabad-211001

[2] A Text book of internal combustion Engines (Including Air compressor, Gas turbines and Jet propulsions) Unit second Edition By R.K.Rajput published by Laxmi Publications Pvt Ltd 113, Golden house,Daryaganj,New Delhi-110002

[3] A Text book of Thermal Engineering by J.K Gupta and R.S.Khurmi 